BJMG 15/1 (2012) 5-10

$10.2478 / \mathrm{v} 10034-012-0001-3$

ORIGINAL ARTICLE

\title{
CYTOGENETIC AND MORPHOLOGICAL ANALYSIS OF DE NOVO ACUTE MYELOID LEUKEMIA IN ADULTS: A SINGLE CENTER STUDY IN JORDAN
}

\author{
Ayesh $\mathrm{MH}^{1, *}$, Khassawneh $\mathrm{B}^{1}$, Matalkah $\mathrm{I}^{2}$, Alawneh $\mathrm{K}^{1}$, Jaradat $\mathrm{S}^{3}$
}

\begin{abstract}
*Corresponding Author: Dr. Mahmoud H. Ayesh (Haj Yousef), Department of Internal Medicine, King Abdullah University Hospital, Faculty of Medicine, Jordan University of Science and Technology, P.O. Box 3030 Irbid 22110, The Hashemite Kingdom of Jordan; Tel.: +962-2-7200-600, Ext. 40713; Fax: +9622-7095-123; E- Mail address: ayesh_mahmoud@yahoo.com
\end{abstract}

\section{ABSTRACT}

Acute myeloid leukemia (AML) in adults is known to be a heterogeneous disease with diverse chromosomal abnormalities. Some of these abnormalities are found with a high incidence in specific ethnic groups and in certain geographical areas. We report the results of cytogenetic studies of 35 adult Jordanian Arab patients with de novo AML diagnosed according to the French-American-British (FAB) criteria. Four patients did not have metaphases secondary to hypocellular bone marrow. The most common morphological subtype was M5 (55\%) followed by M3 (19\%). Cytogenetic abnormalities were present in 20 patients $(65 \%)$; $\mathrm{t}(15 ; 17)$ translocation in six patients $(19 \%)$, inv(16) in four patients $(13 \%), \mathrm{t}(11 ; 17)$ in two patients $(4 \%)$, and the $\mathrm{t}(8 ; 21)$ translocation was not present in any patient. Trisomy 8 was the most common numerical chromosomal abnormality [four patients $(13 \%)$ ].

There were variations and similarities with similar ethninc Arab populations. The most common chromosomal abnormalities were $\mathrm{t}(15 ; 17),+8$ and inv(16). Further and larger crossborder studies are needed.

1 Department of Internal Medicine, King Abdullah University Hospital, Faculty of Medicine, Jordan University of Science and Technology, The Hashemite Kingdom of Jordan

2 Department of Pathology, King Abdullah University Hospital, Irbid, The Hashemite Kingdom of Jordan

3 Department of Biotechnology, King Abdullah University Hospital, Irbid, The Hashemite Kingdom of Jordan
Keywords: Acute myeloid leukemia (AML), Cytogenetics, Translocation, Arabs, Jordan

\section{INTRODUCTION}

Acute myeloid leukemia (AML) is a group of malignant disorders characterized by proliferation and accumulation of immature hematopoietic cells in the bone marrow and the blood. Cytogentic findings in AML are common (50-60\%) and are considered to be important prognostic and diagnostic factors $[1,2]$.

Geographical, ethnic, and environmental influences on the clinical and biological features of AML is crucial in determining the cytogenetic and morphological features of this disease [3-8]. Reports on the cytogenetic and morphological features of AML from Arab populations are scarce $[5,8,9]$. Roberts et al. [5] reported 125 adults with AML from Saudi Arabia, where karyotypic abnormalities were seen in 104 patiets $(52 \%)$ and trisomy 8 being the most common abnormality. In a study from Kuwait on 45 patients with AML, chromosomal abnormalities were reported in $73 \%$, and the most common abnormality was $\mathrm{t}(15,17)$ in $18 \%$ [8]. In 63 ethnic Omani patients with AML, chromosome abnormalities were present in $62 \%$, and the most common abnormalities were $\mathrm{t}(8: 21)$ in $11 \%, \mathrm{t}(15,17)$ in $10 \%$ and trisomy 8 in $11 \%$ [9]. The aim of this study was to report the cytogenetic and morphological features of de novo AML in adult Jordanian Arabs, and to compare the results with similar ethnic Arab populations in other parts of the world. 


\section{MATERIALS AND METHODS}

The study was conducted at the King Abdullah University Hospital (KAUH), Irbid, The Hashemite Kingdom of Jordan. The KAUH is a referral hospital that serves over 1.5 million people, representing $25 \%$ of the Jordanian population [10]. Medical records of adult patients diagnosed with de novo AML were reviewed from September 2002 to April 2010. Chromosomal analysis on bone marrow aspirate was performed on 35 patients. Their age ranged from 16 to 73 years and $65 \%$ were males. Patients who had secondary AML, a previous diagnosis of myelodysplastic syndrome, or less than 16 years old were excluded. The morphological diagnosis of AML was made by a consultant hematopathologist and were based on the French-American-British (FAB) World Health Organization (WHO) criteria $[11,12]$.

The diagnosis of AML was determined by Wright-stained bone marrow smears. Immunophenotyping of the bone marrow aspirate was performed using a panel of monoclonal antibodies (acute lymphoid and myeloid leukemia), consisting of CD11, CD14, CD15, CD33 and CD34 (myeloid markers); $\mathrm{CD} 2, \mathrm{CD} 3, \mathrm{CD} 4, \mathrm{CD} 5$ and CD7 (T-cell linage markers); CD10, CD19, CD20 and CD22 (B-cell lineage markers); and cytoplasmic IgM, CD117 and TdT (pre-B-cell lineage markers).

Bone marrow aspiration samples were cultured for 24 and 48 hours without a mitogen. Conventional GTG-banding techniques were used for metaphase chromosome banding [International System for Human Cytogenetic Nomenclature (ISCN 2005-2009)] $[13,14]$. Cytogenetic abnormalities were identified, performed, and classified according to the ISCN 2005-2009 [13,14].

Patients were identified as having a normal karyotype only after 20 normal metaphases were analyzed. Determination of an abnormal clone required the presence of at least two metaphases with an identical structural rearrangement or an extra chromosome and/or three cells with a missing chromosome $[11,13,14]$. Because of the lack of facilities, we did not perform fluorescent in situ hybridization. Cytogenetic abnormalities were classified according to the type of abnormality, gain or loss of genetic material, and number of abnormalities (one, two, and three or more) $[13,14]$. This study was approved by the Institutional Review Board (IRB) committee of Jordan University Hospital and King Abdullah University Hospital, Irbid, The Hashemite Kingdom of Jordan.

Statistical Analysis. An SAS version 6.2 was used for the data analysis. The chi-square test was performed, and the Yates correction was used where indicated. A $p$ value of $<0.05$ was considered statistically significant.

\section{RESULTS}

Patient Data. Cytogenetic analyses were carried out on 35 consecutive adult de novo AML patients between Septembers 2002 and April 2010. Three patients did not have metaphases due to the presence hypocellular marrow with the AML and one patient had bone marrow necrosis. Thirty-one patients were included in the analysis. The median age at diagnosis was 39 years (mean 40.3 years, range $16-73$ years). The male to female ratio was (65\% males:35\% females).

Morphological Features of Acute Myeloid Leukemia. According to the FAB classification, the morphological subtypes of AML were M5 (17 patients; 55\%), M3 (six patients; 19\%), M4 (four patients; $13 \%$ ), M2 (three patients; $10 \%$ ), and M0 (one patient; 3\%). In the M5 subtype group, 12 patients were males $(71 \%)$.

Cytogenetic Analysis. Cytogenetic abnormalities were observed in 20 patients (65\%). Median age was 35.5 years (range 16-49 years) and male to female ratio was $(60 \%: 40 \%)$. The most common translocation, $\mathrm{t}(15 ; 17)$, was found in six patients $(19 \%), \mathrm{t}(11 ; 17)$ (two patients; 6\%), $\mathrm{t}(9 ; 11)$ (one patient; $3 \%$ ) and $t(7 ; 14)$ (one patient; $3 \%$ ). The inv(16) anomaly was seen in four patients (13\%), $\operatorname{inv}(11)$ in one $(3 \%), \operatorname{inv}(9)$ in one $(3 \%)$ and $\operatorname{inv}(1)$ in one $(3 \%)$. Trisomy 8 was the most frequent numerical chromosomal abnormality (four patients; $13 \%)$. Trisomy 22 was found in two patients $(6 \%)$ and trisomy in one patient $(3 \%)$. Of the losses of chromosomal material, del 7 was seen in one patient $(3 \%)$ and del 11 in one patient $(3 \%)$. Sole karyotype abnormalities were observed in $16 / 31$ patients $(52 \%)$ and karyotypes with combination of abnormalities were observed in $4 / 31$ patients $(13 \%)$. A few unusual abnormalities were observed in our study (Table 1). 
Table 1. Analysis of the characteristics of acute myeloid leukemia patients with abnormal karyotypes.

\begin{tabular}{|c|c|c|c|}
\hline $\begin{array}{l}\text { Subject } \\
\text { Number }\end{array}$ & $\begin{array}{l}\text { Sex- } \\
\text { Age }\end{array}$ & $\begin{array}{c}\text { AML } \\
\text { Subtype }\end{array}$ & $\begin{array}{l}\text { Cytogenetic } \\
\text { Abnormality }\end{array}$ \\
\hline 1 & M-43 & M5 & 22 \\
\hline 2 & M-47 & M5 & $+8, \mathrm{t}(9 ; 11)(\mathrm{p} 22, \mathrm{q} 23)$ \\
\hline 3 & M-34 & M5 & 8 \\
\hline 4 & F-39 & M5 & $\mathrm{t}(11 ; 17)(\mathrm{q} 23 ; \mathrm{q} 25)$ \\
\hline 5 & M-48 & M5 & $\mathrm{t}(11 ; 17)(\mathrm{q} 23 ; 25)$ \\
\hline 6 & M-44 & M5 & $\mathrm{t}(7 ; 14)(\mathrm{q} 33 ; \mathrm{q} 32)$ \\
\hline 7 & M-34 & M5 & 8 \\
\hline 8 & F-17 & M5 & $\begin{array}{l}\operatorname{inv}(1)(\mathrm{p} 13 \mathrm{q} 32) \operatorname{del}(7) \\
\mathrm{q} 22 ; \mathrm{q} 23), \operatorname{del}(11) \\
(\mathrm{p} 11 ; \mathrm{q} 12)\end{array}$ \\
\hline 9 & M-16 & M4 & $\begin{array}{c}\text { in }(16)(\mathrm{p} 13 ; \mathrm{q} 13) / 81-92 \\
\text { XXYY }\end{array}$ \\
\hline 10 & $\mathrm{~F}-21$ & M4E & $\operatorname{inv}(16)(\mathrm{p} 13 ; \mathrm{q} 22)$ \\
\hline 11 & M-38 & M4E & $\begin{array}{c}+8 . \operatorname{inv}(16) \\
(\mathrm{p} 13 ; \mathrm{q} 23),+21\end{array}$ \\
\hline 12 & F-42 & M4E & $\operatorname{inv}(16),+22$ \\
\hline 13 & F-35 & M3 & $\mathrm{t}(15 ; 17)(\mathrm{q} 22 ; \mathrm{q} 13)$ \\
\hline 14 & $\mathrm{~F}-48$ & M3 & $\mathrm{t}(15 ; 17)(\mathrm{q} 22 ; \mathrm{q} 13)$ \\
\hline 15 & $\mathrm{~F}-45$ & M3 & $\mathrm{t}(15 ; 17)(\mathrm{q} 22 ; \mathrm{q} 13)$ \\
\hline 16 & F-19 & M3 & $\mathrm{t}(15 ; 17)(\mathrm{q} 22 ; \mathrm{q} 13)$ \\
\hline 17 & M-49 & M3 & $\mathrm{t}(15 ; 17)(\mathrm{q} 22 ; \mathrm{q} 13)$ \\
\hline 18 & M-21 & M3 & $\mathrm{t}(15 ; 17)(\mathrm{q} 22 ; \mathrm{q} 13)$ \\
\hline
\end{tabular}

Normal karyotypes were observed in 11 patients $(35 \%)$. The median age was 51 years (range 25-73 years). According to the FAB classification, nine patients had M5 and two had M2 (Table 2).

\section{DISCUSSION}

This is the first report on the cytogenetic abnormalities of de novo AML in adult ethnic Arabs in Jordan. The M5 anomaly was the most frequent morphological subtype. Cytogenetic abnormalities were common and observed in $65 \%$ of our patients. The most frequent balanced translocation was $\mathrm{t}(15 ; 17)$ and trisomy 8 was the most common numerical chromosomal abnormality.

The median age for our patients was 39 years, which is similar to reports from other Arab populations in the region $[5,8,9]$. The median age in stud-
Table 2. Characteristics of acute myeloid leukemia patients with normal karyotypes.

\begin{tabular}{|c|c|c|}
\hline Subject Number & Sex-Age & AML Subtype \\
\hline 1 & F-51 & M5 \\
\hline 2 & M-38 & M5 \\
\hline 3 & M-63 & M5 \\
\hline 4 & M-65 & M5 \\
\hline 5 & M-67 & M5 \\
\hline 6 & M-34 & M5 \\
\hline 7 & F-34 & M5 \\
\hline 8 & F-73 & M5 \\
\hline 9 & M-67 & M5 \\
\hline 10 & M-25 & M2 \\
\hline 11 & M-49 & M2 \\
\hline
\end{tabular}

ies from western populations is in the range of 5863 years, with the majority of patients being older than 55 years $[3,15,16]$. In contrast, the median age of patients at the time of diagnosis of AML tend to be younger in developing countries [5,8,9,16-19]. The explanation for the difference between age at diagnosis in patients from different geographical regions is not clear. This may be explained by the effect of ethnic, geographical and environmental factors. Similar to other studies from western countries and Arab populations there was a clear male predominance $[9,15]$.

In this study, M5 was the most frequent morphological subtype (55\%) followed by M3 (19\%). In Saudi Arabia, M4 was the most common subtype $(39 \%)$, in Oman it was M2 (35\%) and in Kuwait it was M3 $(23 \%)[5,8,9]$.

Cytogenetic abnormalities were observed in $65 \%$ of our patients, comparable to other studies from similar Arab populations (52-73\%) [5,8,9], and large studies from different parts of the world $(52-78 \%)[3,15,16]$. In our study, $t(15 ; 17)$ was the most frequently obsereverd balanced translocation. This was similar to that found in Kuwat [8]. Whereas in Saudi Arabia, $\mathrm{t}(8 ; 21)$ was the most frequent balanced translocation [5], and $\mathrm{t}(8 ; 21)$ and $\mathrm{t}(15 ; 17)$ were the most frequent translocations in Oman [9]. The most frequent numerical abnormality in this study was the gain of chromosome $8(13 \%)$, which is similar to that found in Saudi Arabia and Oman $[5,9]$. The inv(16) inversion was seen in $13 \%$ of our 
patients, which is higher than reported in similar ethnic groups $[5,8,9]$. The absence of the $t(8 ; 21)$ translocation in our patients may be explained by the low percentage (9\%) of the M2 subtype obsereved in this study. As with other reports, several unusual abnormalities were seen in this study.

Compared to similar reports on ethnic Arabs from the region, there were similarities and variations of the age, gender, and morphologic subtype and chromosomal abnormalities in ethnic Arabs in Jordan with de novo AML. The observed similarities could be explained by the common ethnic, environmental and geographic factors. Further large and crossborder studies are needed to elucidate the cytogenetic pattern of this disease, and to better understand the effects of ethnic and geographical factors that may underlie the biological diversity of AML.

\section{ACKNOWLEDGMENTS}

We would like to thank Ola Tainy, Faten Atrooze, Elham Ababneh, and Einas Diab from the Department of Pathology at the King Abdullah University Hospital, Irbid, The Hashemite Kingdom of Jordan, for making the cytogenetic and flow cytometry data available.

Declaration of Interest. The authors report no conflicts of interest. The authors alone are responsible for the content and writing of this article. This study had no financial support.

\section{REFERENCES}

1. Bloomfield CD, Goldman A, Hasafeld D, de la Chapele A. Fourth International Workshop on Chromosomes in Leukemia 1982: clinical significance of chromosomal abnormalities in acute non lymphoblastic leukemia. Cancer Genet Cytogenet. 1984; 11(3): 332-350.

2. Grimwade D, Hills RK, Moorman AV, Walker H, Chatters S, Goldstone AH, Wheatley K, Harrison CJ, Burnett AK; National Cancer Research Institute Adult Leukaemia Working Group. Refinement of cytogenetic classification in acute myeloid leukemia: determination of prognostic significance of rare recurring chromosomal abnormalities among 5876 younger adult patients treated in the United Kingdom Medical Research Council trials. Blood. 2010; 116(3): 354-365.

3. Preiss BS, Kerndrup GB, Schmidt KG, Sørensen AG, Clausen NA, Gadeberg OV, Mourits-Ander- sen T, Pedersen NT; AML Study Group Region of Southern Denmark. Cytogenetic findings in adult de novo acute myeloid leukaemia: a populationbased study of 303/307 patients. Br J Haematol. 2003; 123(2): 219-234.

4. Nakase K, Bradstock K, Sartor M, Gottlieb D, Byth K, Kita K, Shiku H, Kamada N. Geographic heterogeneity of cellular characteristics of acute myeloid leukemia: a comparative study of Australian and Japanese adult cases. Leukemia. 2000; 14(1): 163-168.

5. Roberts GT, Spence DG, Padmos MA, Sheth KV, Clink H, Ernst P. Morphologic immunophenotypic and cytogenetic patterns of adult myeloid leukemia in Saudi Arabia. Leuk Res. 1992; 16(2): 181-190.

6. Arana-Trejo RM, Gómez-Morales E, Rubio-Borja ME, Kassack-Ipiña JJ, Cervantes-Peredo A, Guerrero-Rivera S, González-Llaven J, GutiérrezRomero M, Pizzuto-Chávez J, Kofman-Alfaro S. Cytogenetic findings in 303 Mexican patients with de novo acute myeloblastic leukemia. Arch Med Res. 1997; 28(2): 209-214.

7. Douer D, Preston-Martin S, Chang E, Nichols PW, Watkins KJ, Levine AM. High frequency of acute promyelocytic leukemia among Latinos with acute myeloid leukemia. Blood. 1996; 87(1): 308-313.

8. Al Bahar S, Pandita R, Bavishi K, Kreze O, Nath S. Chromosome aberrations in de novo acute myeloid leukemia patients in Kuwait. Neoplasma. 2004; 51(3): 223-227.

9. Udayakumar AM, Pathare AV, Al-Kindi S, Khan H, Rehmen JU, Zia F, Al-Ghazaly A, Nusrut N, Khan MI, Wali YA, Al-Lamki Z, Dennison D, Raeburn JA. Cytogenetic, morphological, and immunophenotypic patterns in Omani patients with de novo acute myeloid leukemia. Cancer Genet Cytogenet. 2007; 177(2): 89-94.

10. Jordan In Figures 2010. Department of Statistics - Jordan [Internet]. Amman, Jordan. 2010 [cited 2011Dec 19]. Available from: http://www.dos.gov.jo/.

11. Bennett JM, Catovsky D, Daniel MT, Flandrin G, Galton DA, Gralnick HR, Sultan C. Proposed revised criteria for the classification of acute myeloid leukemia: a report of the French-American-British Cooperative group. Ann Intern Med. 1985; 103(45): 620-625.

12. Vardiman JW, Thiele J, Arber DA, Brunning RD, Borowitz MJ, Porwit A, Harris NL, Le Beau MM, Hellström-Lindberg E, Tefferi A, Bloomfield CD. The 2008 revision of the World Health Organization (WHO) classification of myeloid neoplasms and acute leukemia: rationale and important changes. Blood. 2009; 114(5): 937-951.

13. ISCN 2005: an international system for human cytogenetic nomenclature (2005). In: Shaffer LG, Tommerup N, Eds. Basel: S. Karger, 2005. 
14. ISCN 2009: an international System for human cytogenetic nomenclature (2009). In: Shaffer LG, Slovak ML, Campbell LJ, Eds. Basel: S. Karger, 2009.

15. Mauritzson N, Johansson B, Albin M, Billstrom R, Ahlgren T, Mikoczy Z, Nilsson PG, Hagmar L, Mitelman F. A single-center population-based consecutive series of 1500 cytogenetically investigated adult hematological malignancies: karyotypic features in relation to morphology, age and gender. Eur J Haematol. 1999; 62(2): 95-102.

16. Deschler B, Lübbert M. Acute myeloid leukemia: epidemiology and etiology. Cancer. 2006; 107(9): 2099-2107.
17. Rego MF, Pinheiro GS, Metze K, Lorand-Metze I. Acute leukemias in Piaui: a comparison with features observed in other regions of Brazil. Braz J Med Biol Res. 2003; 36(3): 331-337.

18. Acevedo S, Slavutsky I, Andreoli G, Larripa I. Cytogenetic study of 50 de novo cases of ANLL from Argentina. Haematologica. 1994; 79(1): 40-45.

19. So CC, Wan TS, Chow JL, Hui KC, Choi WW, Lam CC, Chan LC. Cancer Genet. A single-center cytogenetic study of 629 Chinese patients with de novo acute myeloid leukemia - evidence of major ethnic differences and a high prevalence of acute promyelocytic leukemia in Chinese patients. Cancer Genet. 2011; 204(8): 430-438. 
